\title{
ARTICLE
}

Received 27 Jun 2014 | Accepted 20 Nov 2014 | Published 8 Jan 2015

\section{Generation of spin currents by surface plasmon resonance}

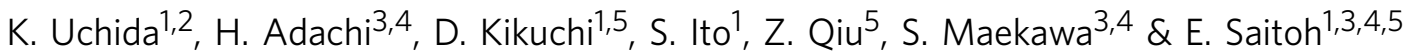

Surface plasmons, free-electron collective oscillations in metallic nanostructures, provide abundant routes to manipulate light-electron interactions that can localize light energy and alter electromagnetic field distributions at subwavelength scales. The research field of plasmonics thus integrates nano-photonics with electronics. In contrast, electronics is also entering a new era of spintronics, where spin currents play a central role in driving devices. However, plasmonics and spin-current physics have so far been developed independently. Here we report the generation of spin currents by surface plasmon resonance. Using $\mathrm{Au}$ nanoparticles embedded in $\mathrm{Pt} / \mathrm{BiY}_{2} \mathrm{Fe}_{5} \mathrm{O}_{12}$ bilayer films, we show that, when the $\mathrm{Au}$ nanoparticles fulfill the surface-plasmon-resonance conditions, spin currents are generated across the $\mathrm{Pt} / \mathrm{BiY}_{2} \mathrm{Fe}_{5} \mathrm{O}_{12}$ interface. This spin-current generation cannot be explained by conventional heating effects, requiring us to introduce nonequilibrium magnons excited by surface-plasmon-induced evanescent electromagnetic fields in $\mathrm{BiY}_{2} \mathrm{Fe}_{5} \mathrm{O}_{12}$. This plasmonic spin pumping integrates surface plasmons with spin-current physics, opening the door to plasmonic spintronics.

\footnotetext{
${ }^{1}$ Institute for Materials Research, Tohoku University, Sendai 980-8577, Japan. ${ }^{2}$ PRESTO, Japan Science and Technology Agency, Saitama 332-0012, Japan. ${ }^{3}$ Advanced Science Research Center, Japan Atomic Energy Agency, Tokai 319-1195, Japan. ${ }^{4}$ CREST, Japan Science and Technology Agency, Tokyo 102-0075, Japan. ${ }^{5}$ WPI Advanced Institute for Materials Research, Tohoku University, Sendai 980-8577, Japan. Correspondence and requests for materials should be addressed to K.U. (email: kuchida@imr.tohoku.ac.jp).
} 
S urface plasmons enable subdiffraction-limit localization of light and strong enhancement of electromagnetic fields. Owing to this feature, plasmonics ${ }^{1-5}$ has vast potential in solar cells, light generation, microscopy, data storage and biosensors. One of the other emerging developments in this field is magneto-plasmonics ${ }^{6,7}$, which offers unique possibilities to manipulate light by the use of external magnetic fields or magnetic materials. Important topics in magneto-plasmonics include the enhancement of magneto-optical effects in plasmonic nanostructures ${ }^{6}$, influence of magnetic fields on surface plasmon resonance (SPR) and observation of SPR in ferromagnetic metals ${ }^{7}$. However, the integration of plasmonics into spintronics $^{8,9}$ is yet to be realized, and the interaction between surface plasmons and spin currents ${ }^{10,11}$ contains unexplored physics.

In the field of spintronics, for spin-current generation, we often rely on a spin pumping effect ${ }^{12-15}$, which refers to the transfer of spin-angular momentum from magnetization dynamics in a ferromagnet to conduction-electron spins in an attached paramagnet; when a motion of magnetic moments in the ferromagnet is excited, a spin current is pumped out of the ferromagnet into the paramagnet.

Recent studies in spintronics have revealed that there are two types of spin pumping effects. One is coherent spin pumping, which is due to coherent phase precession of the magnetization, that is, ferromagnetic or spin-wave resonances in ferromagnets typically excited by microwave irradiation ${ }^{13-15}$. The other is incoherent spin pumping, which is due to a nonequilibrium state of spins at a ferromagnet/paramagnet interface excited by incoherent external perturbations; when magnons in the ferromagnet and/or electrons in the paramagnet deviate from thermal equilibrium, a net spin current is generated across the interface. A typical example of the incoherent spin pumping is the spin Seebeck effect ${ }^{16-24}$, where the magnon/electron distribution functions are modulated by external temperature gradients.
In this work, we report the observation of plasmonic spin pumping; we show that the incoherent spin pumping can be driven by surface plasmons under visible light illumination. This plasmonic spin pumping will invigorate research in both the fields of spintronics and plasmonics, paving the way to create new devices, such as solar spin-current generators and spin-based plasmonic sensors.

\section{Results}

Device structure. Figure 1a shows a schematic illustration of the sample system used in the present study. The sample consists of a paramagnetic $\mathrm{Pt} /$ ferrimagnetic $\mathrm{BiY}_{2} \mathrm{Fe}_{5} \mathrm{O}_{12}$ bilayer film with $\mathrm{Au}$ nanoparticles (NPs) embedded in the $\mathrm{BiY}_{2} \mathrm{Fe}_{5} \mathrm{O}_{12}$ layer. The $\mathrm{Au}$ NPs with an in-plane diameter of $30-90 \mathrm{~nm}$ and a height of 20-50 nm were formed by heating a $\mathrm{Au}$ thin film ${ }^{6}$ on a singlecrystalline $\mathrm{Gd}_{3} \mathrm{Ga}_{5} \mathrm{O}_{12}$ (111) substrate (Fig. 2b,c). The 110-nmthick $\mathrm{BiY}_{2} \mathrm{Fe}_{5} \mathrm{O}_{12}$ film was then coated on them by means of a metal-organic decomposition (MOD) method $^{22}$ (see Methods). Finally, a 5-nm-thick Pt film was sputtered on to the $\mathrm{BiY}_{2} \mathrm{Fe}_{5} \mathrm{O}_{12}$ film. To excite surface plasmons, the $\mathrm{Pt} / \mathrm{BiY}_{2} \mathrm{Fe}_{5} \mathrm{O}_{12} / \mathrm{Au}-\mathrm{NP}$ sample was illuminated with unpolarized monochromatic light with wavelength $\lambda(400-770 \mathrm{~nm})$ and power $P$ from the Pt-film side at normal incidence (Fig. 1a). As the Pt and $\mathrm{BiY}_{2} \mathrm{Fe}_{5} \mathrm{O}_{12}$ layers are very thin, the light passes through the layers and interacts with the Au NPs. We checked that the electric resistance between the ends of the $\mathrm{BiY}_{2} \mathrm{Fe}_{5} \mathrm{O}_{12}$ layer with $\mathrm{Au}$ NPs under the light illumination is much greater than the measurement limit of our electrometer $\left(>2 \times 10^{11} \Omega\right.$ ) at all the $\lambda$ values; the possibility of optical charge-carrier generation in $\mathrm{BiY}_{2} \mathrm{Fe}_{5} \mathrm{O}_{12}$ is excluded.

In Fig. 1c, we show the light-transmittance spectrum of the $\mathrm{Pt} / \mathrm{BiY}_{2} \mathrm{Fe}_{5} \mathrm{O}_{12} / \mathrm{Au}-\mathrm{NP}$ sample (see the blue circle data points). We found that the sample exhibits a clear dip structure in the transmittance spectrum around $\lambda=690 \mathrm{~nm}$ in comparison with the spectra of a $\mathrm{Gd}_{3} \mathrm{Ga}_{5} \mathrm{O}_{12}$ substrate, a plain $\mathrm{Pt}$ film and
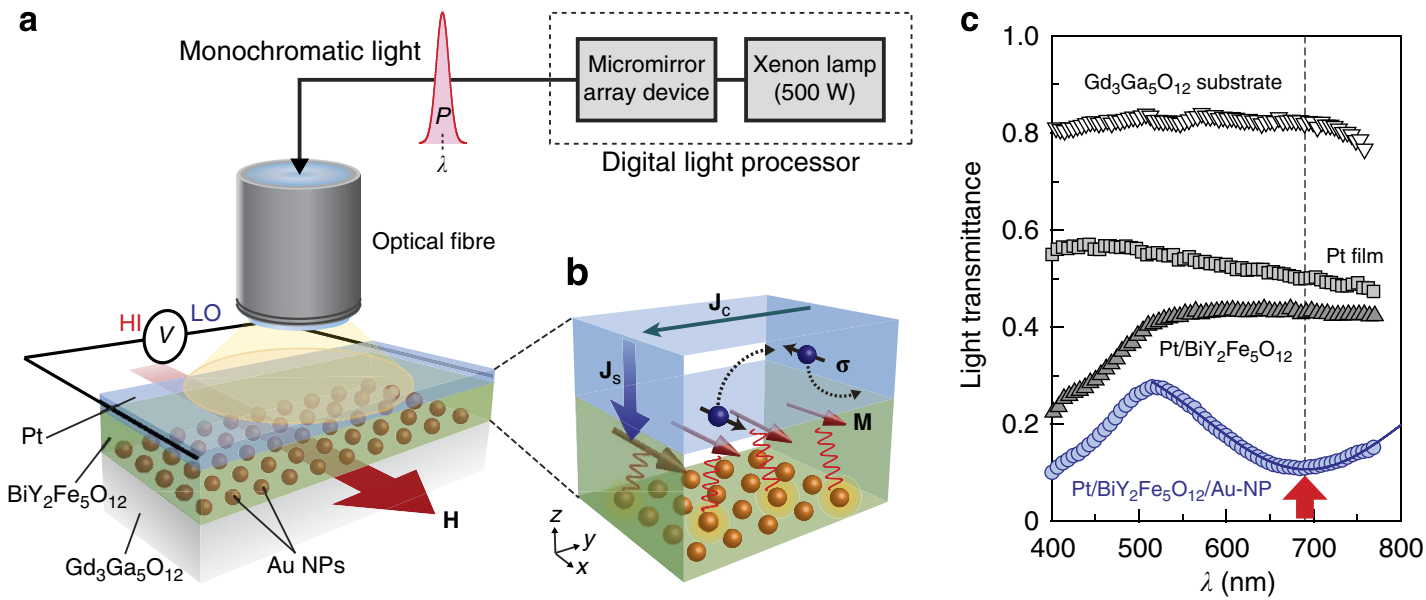

Figure 1 | Experimental set-up and device structure. (a) A schematic illustration of the $\mathrm{Pt} / \mathrm{BiY}_{2} \mathrm{Fe}_{5} \mathrm{O}_{12} / \mathrm{Au}$-nanoparticle (NP) sample and experimental configuration for measuring the plasmonic spin pumping. The $\mathrm{Pt} / \mathrm{BiY}_{2} \mathrm{Fe}_{5} \mathrm{O}_{12} / \mathrm{Au}-\mathrm{NP}$ sample is of a $10 \mathrm{~mm} \times 5 \mathrm{~mm}$ rectangular shape. The sample was illuminated with monochromatic light with the wavelength $\lambda(400-770 \mathrm{~nm})$, power $P$, bandwidth of $20 \mathrm{~nm}$ and spot diameter of $\sim 5 \mathrm{~mm}$ from the Pt-film side at normal incidence by using a digital light processor comprising a $500 \mathrm{~W}$ Xenon lamp and a micromirror array device (Gooch \& Housego, OL490). $\mathrm{HI}$ and LO represent the inputs of a voltmeter. $\mathbf{H}$ denotes the external magnetic field vector (red arrow) with the magnitude $H$. (b) Plasmonic spin pumping and inverse spin Hall effect (ISHE) in the Pt/BiY ${ }_{2} \mathrm{Fe}_{5} \mathrm{O}_{12} / \mathrm{Au}-\mathrm{NP}$ sample. Here, $\mathbf{M}, \mathbf{J}_{\mathrm{C}}, \mathbf{J}_{\mathrm{S}}$ and $\boldsymbol{\sigma}$ denote the magnetization vector (dark red arrows), charge current generated by the ISHE (green arrow), spatial direction of the spin current generated by the plasmonic spin pumping (blue arrow) and spin-polarization vector of the spin current (black arrows), respectively. Blue (orange) spheres schematically show electron charge (Au NPs). Black dotted arrows and red wavy lines schematically show the trajectory of the electrons and the interaction between magnetic moments in the $\mathrm{BiY}_{2} \mathrm{Fe}_{5} \mathrm{O}_{12}$ layer and evanescent electromagnetic fields induced by the surface plasmon resonance (SPR), respectively. (c) $\lambda$ dependence of the light transmittance of the $0.5-\mathrm{mm}-\mathrm{thick}_{\mathrm{G}} \mathrm{G}_{3} \mathrm{Ga}_{5} \mathrm{O}_{12}$ substrate, 5-nm-thick Pt film on the $\mathrm{Gd}_{3} \mathrm{Ga}_{5} \mathrm{O}_{12}$ substrate, $\mathrm{Pt} / \mathrm{BiY}_{2} \mathrm{Fe}_{5} \mathrm{O}_{12}$ sample and $\mathrm{Pt} / \mathrm{BiY}_{2} \mathrm{Fe}_{5} \mathrm{O}_{12} / \mathrm{Au}-\mathrm{NP}$ sample. In the $\mathrm{Pt} / \mathrm{BiY}_{2} \mathrm{Fe}_{5} \mathrm{O}_{12}$ sample, the Pt and $\mathrm{BiY} \mathrm{Fe}_{5} \mathrm{O}_{12}$ films were formed directly on the $\mathrm{Gd}_{3} \mathrm{Ga}_{5} \mathrm{O}_{12}$ substrate without Au NPs. A blue solid curve was obtained by fitting the observed dip structure using a Gaussian function. A red arrow shows the wavelength at which the SPR is excited in the $\mathrm{Pt} / \mathrm{BiY}_{2} \mathrm{Fe}_{5} \mathrm{O}_{12} / \mathrm{Au}-\mathrm{NP}$ sample. 


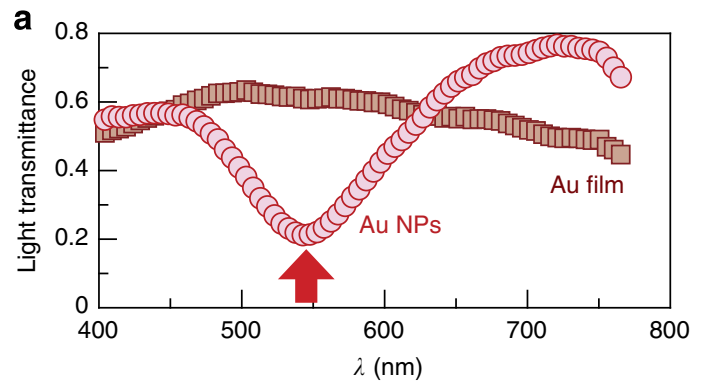

b

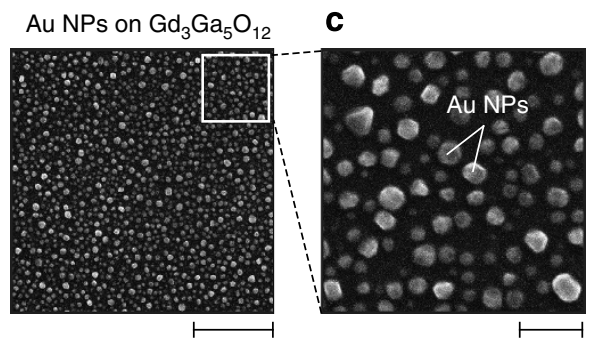

Figure 2 | Au nanoparticles. (a) $\lambda$ dependence of the light transmittance of a 15 -nm-thick $\mathrm{Au}$ film and $\mathrm{Au}$ NPs on the $\mathrm{Gd}_{3} \mathrm{Ga}_{5} \mathrm{O}_{12}$ substrate.

The light-transmittance spectrum of the Au-NP sample exhibits a clear dip structure due to the SPR, while that of the Au film does not exhibit strong $\lambda$ dependence. The position of the SPR wavelength for the Au-NP sample is marked with a red arrow. (b) Scanning electron microscope image of $\mathrm{Au}$ $\mathrm{NPs}$ on the $\mathrm{Gd}_{3} \mathrm{Ga}_{5} \mathrm{O}_{12}$ substrate, measured before forming the $\mathrm{BiY}_{2} \mathrm{Fe}_{5} \mathrm{O}_{12}$ and Pt layers. (c) Magnified scanning electron microscope image of the $\mathrm{Au}$ NPs on the $\mathrm{Gd}_{3} \mathrm{Ga}_{5} \mathrm{O}_{12}$ substrate. The scale bars in (b) and (c) represent $1 \mu \mathrm{m}$ and $200 \mathrm{~nm}$, respectively.

$\mathrm{Pt} / \mathrm{BiY}_{2} \mathrm{Fe}_{5} \mathrm{O}_{12}$ sample without Au NPs. This dip structure for the $\mathrm{Pt} / \mathrm{BiY}_{2} \mathrm{Fe}_{5} \mathrm{O}_{12} / \mathrm{Au}-\mathrm{NP}$ sample is attributed to the excitation of localized SPR ${ }^{1,2}$ in the Au NPs embedded in the $\mathrm{BiY}_{2} \mathrm{Fe}_{5} \mathrm{O}_{12}$ layer (see also Fig. 2a).

Electromagnetic field distributions. To visualize the SPR in the $\mathrm{BiY}_{2} \mathrm{Fe}_{5} \mathrm{O}_{12} / \mathrm{Au}-\mathrm{NP}$ structure, we performed electromagnetic field simulations by means of a finite-difference time-domain (FDTD) $\operatorname{method}^{25}$. Figure $3 \mathrm{a}$ shows a schematic illustration of a $\mathrm{BiY}_{2} \mathrm{Fe}_{5} \mathrm{O}_{12} / \mathrm{Au}-\mathrm{NP}$ model used for the FDTD simulations (see Methods for details). As shown in Fig. 3b, under the SPR condition $(\lambda=690 \mathrm{~nm})$, strong evanescent electromagnetic fields, that is, near fields ${ }^{1,2}$, are generated in the $\mathrm{BiY}_{2} \mathrm{Fe}_{5} \mathrm{O}_{12}$ film in the vicinity of the $\mathrm{BiY}_{2} \mathrm{Fe}_{5} \mathrm{O}_{12} / \mathrm{Au}-\mathrm{NP}$ interface, while the enhancement and localization of electromagnetic fields do not appear at $\lambda=500 \mathrm{~nm}$ (Fig. 3c), consistent with the lighttransmittance spectrum of the $\mathrm{Pt} / \mathrm{BiY}_{2} \mathrm{Fe}_{5} \mathrm{O}_{12} / \mathrm{Au}-\mathrm{NP}$ sample in Fig. 1c. The FDTD simulations also show that the evanescent electromagnetic fields in the $\mathrm{BiY}_{2} \mathrm{Fe}_{5} \mathrm{O}_{12}$ layer due to the SPR are not affected by the presence of the Pt layer irrespective of the position and size of Au NPs (Supplementary Figs 1 and 2).

Measurement mechanism of plasmonic spin pumping. In the $\mathrm{Pt} / \mathrm{BiY}_{2} \mathrm{Fe}_{5} \mathrm{O}_{12} / \mathrm{Au}-\mathrm{NP}$ sample, if the evanescent electromagnetic fields concomitant with surface plasmons in $\mathrm{Au}$ NPs excite magnons in the $\mathrm{BiY}_{2} \mathrm{Fe}_{5} \mathrm{O}_{12}$ film and the excited magnons drive the incoherent spin pumping, a spin current is generated in the $\mathrm{Pt}$ layer with the spatial direction $\mathbf{J}_{S}$ and the spin-polarization vector $\boldsymbol{\sigma}$ parallel to the magnetization $\mathbf{M}$ of the $\mathrm{BiY}_{2} \mathrm{Fe}_{5} \mathrm{O}_{12}$ film (Fig. 1b). This plasmon-induced spin current is converted into a d.c. charge current $\mathbf{J}_{\mathrm{C}}$ due to the inverse spin Hall effect (ISHE) ${ }^{14,26,27}$ in the Pt layer owing to the strong spin-orbit interaction in Pt. When $\mathbf{M}$ of the $\mathrm{BiY}_{2} \mathrm{Fe}_{5} \mathrm{O}_{12}$ film is along the $x$

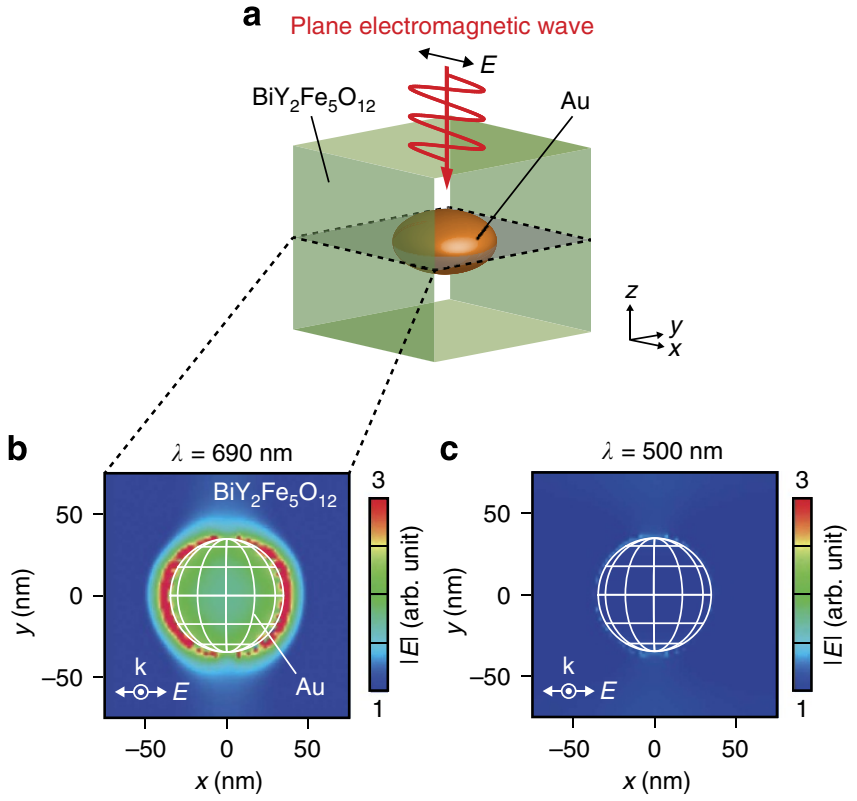

Figure 3 | Numerical calculation. (a) A schematic illustration of the $\mathrm{BiY}_{2} \mathrm{Fe}_{5} \mathrm{O}_{12} / \mathrm{Au}-\mathrm{NP}$ model used for the numerical calculation based on a finite-difference time-domain method. Plane electromagnetic waves with the polarization along the $x$ direction and the wave vector $\mathbf{k}$ along the $z$ direction are applied to the $\mathrm{BiY}_{2} \mathrm{Fe}_{5} \mathrm{O}_{12} / \mathrm{Au}-\mathrm{NP}$ model. $E$ denotes an electric field of the electromagnetic waves. $(\mathbf{b}, \mathbf{c})$ Simulated distributions of the electric field intensity $|E|$ in the $\mathrm{BiY}_{2} \mathrm{Fe}_{5} \mathrm{O}_{12} / \mathrm{Au}-\mathrm{NP}$ model in the $x$ - $y$ plane across the centre of the Au NP at $\lambda=690 \mathrm{~nm}$ (b) and $500 \mathrm{~nm}$ (c).

direction, $\mathbf{J}_{\mathrm{C}}$ is generated along the $y$ direction because of the following ISHE symmetry:

$$
\mathbf{J}_{\mathrm{C}} \propto \mathbf{J}_{\mathrm{S}} \times \sigma
$$

where the $x, y$ and $z$ directions are defined in Fig. 1b. We note that extrinsic artefacts induced by a static magnetic proximity effect $^{28}$ at the $\mathrm{Pt} / \mathrm{BiY}_{2} \mathrm{Fe}_{5} \mathrm{O}_{12}$ interface are negligibly small in the present structure 23,24 . To detect the ISHE induced by the plasmonic spin pumping, we measured an electric voltage $V$ between the ends of the Pt layer under open circuit condition while illuminating with monochromatic light and applying an external magnetic field $\mathbf{H}$ (with the magnitude $H$ ) to the $\mathrm{Pt} / \mathrm{BiY}_{2} \mathrm{Fe}_{5} \mathrm{O}_{12} / \mathrm{Au}-\mathrm{NP}$ sample along the $x$ - $y$ plane (Fig. 1a). All of the $V$ measurements were carried out at room temperature and atmospheric pressure.

Observation of plasmonic spin pumping. To observe the plasmonic spin pumping, it is important to separate the plasmoninduced signals from extrinsic heating effects. First of all, to check the heating effect due to the light illumination, we measured the voltage in the $\mathrm{Pt} / \mathrm{BiY}_{2} \mathrm{Fe}_{5} \mathrm{O}_{12}$ sample without $\mathrm{Au}$ NPs. The grey triangle data points in Fig. $4 \mathrm{~b}$ show the $\lambda$ dependence of the voltage normalized by the incident light power, $V / P$, in the $\mathrm{Pt} / \mathrm{BiY}_{2} \mathrm{Fe}_{5} \mathrm{O}_{12}$ sample at $H=200$ Oe. When $\mathbf{H}$ is applied along the $x$ direction, a finite voltage signal appears in the Pt layer at all the $\lambda$ values. Because of the absence of $\mathrm{Au}$ NPs and surface plasmons, the signal in the $\mathrm{Pt} / \mathrm{BiY}_{2} \mathrm{Fe}_{5} \mathrm{O}_{12}$ sample is attributed to the heating of the sample by the light illumination, that is, the longitudinal spin Seebeck effect ${ }^{20,22-24}$ (see also Supplementary Fig. 3). Here, the sign of the $V / P$ signal shows that the temperature of the Pt layer is higher than that of the $\mathrm{BiY}_{2} \mathrm{Fe}_{5} \mathrm{O}_{12}$ layer under the light illumination (Supplementary Fig. 4 and Supplementary Note 1). Importantly, this heating signal in the $\mathrm{Pt} / \mathrm{BiY}_{2} \mathrm{Fe}_{5} \mathrm{O}_{12}$ sample does not exhibit strong $\lambda$ dependence (Fig. $4 \mathrm{~b}$ ). 

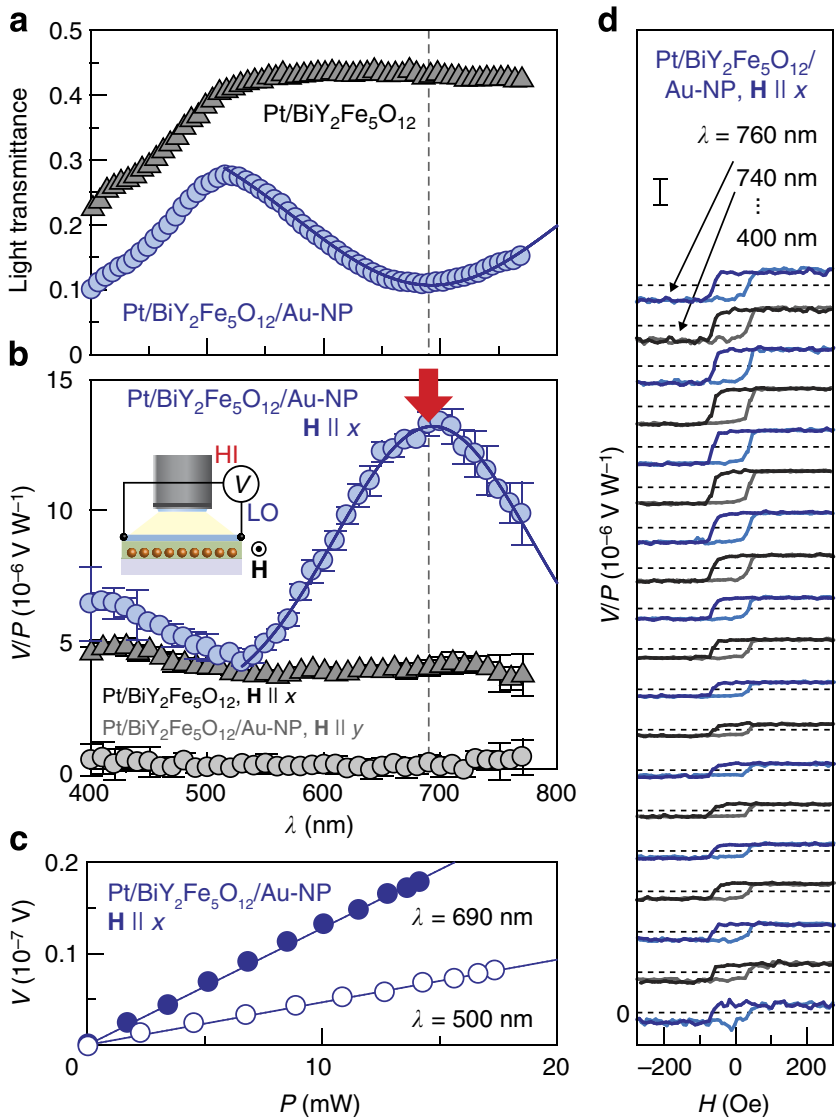

Figure 4 | Observation of plasmonic spin pumping. (a) $\lambda$ dependence of the light transmittance of the $\mathrm{Pt} / \mathrm{BiY}_{2} \mathrm{Fe}_{5} \mathrm{O}_{12} / \mathrm{Au}-\mathrm{NP}$ and $\mathrm{Pt} / \mathrm{BiY}_{2} \mathrm{Fe}_{5} \mathrm{O}_{12}$ samples. The samples were prepared at the same time. (b) $\lambda$ dependence of the electric voltage between the ends of the Pt layer normalized by the incident light power, $\mathrm{V} / \mathrm{P}$, in the $\mathrm{Pt} / \mathrm{BiY}_{2} \mathrm{Fe}_{5} \mathrm{O}_{12} / \mathrm{Au}-\mathrm{NP}$ and $\mathrm{Pt} / \mathrm{BiY}_{2} \mathrm{Fe}_{5} \mathrm{O}_{12}$ samples, measured when $\mathbf{H}$ of $H=200$ Oe was applied along the $x$ or $y$ direction. The in-plane coercive force of the $\mathrm{BiY}_{2} \mathrm{Fe}_{5} \mathrm{O}_{12}$ layer is around $30 \mathrm{Oe}$; the magnetization of $\mathrm{BiY}_{2} \mathrm{Fe}_{5} \mathrm{O}_{12}$ is aligned along the $\mathbf{H}$ direction at $H=200$ Oe. The position of the SPR wavelength is marked with a red arrow. A blue solid curve was obtained by fitting the observed peak voltage structure using a Gaussian function. The error bars represent the s.d. of the measurements. (c) $P$ dependence of $V$ in the Pt/BiY ${ }_{2} \mathrm{Fe}_{5} \mathrm{O}_{12} / \mathrm{Au}-\mathrm{NP}$ sample at $\lambda=690 \mathrm{~nm}$ and $500 \mathrm{~nm}$, measured when $\mathbf{H}$ of $H=200 \mathrm{Oe}$ was applied along the $x$ direction. (d) $H$ dependence of V/P in the $\mathrm{Pt} / \mathrm{BiY}_{2} \mathrm{Fe}_{5} \mathrm{O}_{12} / \mathrm{Au}-\mathrm{NP}$ sample for various values of $\lambda(=760,740, \ldots$, $400 \mathrm{~nm}$ ), measured when $\mathbf{H}$ was along the $x$ direction. The scale bar represents $V / P=20 \times 10^{-6} \vee W^{-1}$. The dark blue and black lines (light blue and grey lines) show the $V / P$ signals measured when $\mathbf{H}$ was swept from positive to negative (from negative to positive).

Now we are in a position to investigate the plasmonic generation of spin currents. The blue circle data points in Fig. $4 \mathrm{~b}$ are the $V / P$ spectrum in the $\mathrm{Pt} / \mathrm{BiY}_{2} \mathrm{Fe}_{5} \mathrm{O}_{12}$ film that contains $\mathrm{Au} \mathrm{NPs}$. Also in this $\mathrm{Pt} / \mathrm{BiY}_{2} \mathrm{Fe}_{5} \mathrm{O}_{12} / \mathrm{Au}-\mathrm{NP}$ sample, when $\mathbf{H} \| x$, the $V / P$ signal appears with the same sign (Fig. 4b) and the magnitude of $V$ is proportional to the light power $P$ (Fig. 4c). The sign of the signal at each $\lambda$ was observed to be reversed by reversing $H$ with a hysteresis loop, indicating that the signal is affected by the $\mathbf{M}$ direction of the $\mathrm{BiY}_{2} \mathrm{Fe}_{5} \mathrm{O}_{12}$ layer (Fig. 4d). As also shown in Fig. 4b, we confirmed that the $V / P$ signal disappears when $\mathbf{H}$ is applied along the $y$ direction, consistent with equation (1). These results indicate that the observed $V / P$ signal in the $\mathrm{Pt} / \mathrm{BiY}_{2} \mathrm{Fe}_{5} \mathrm{O}_{12} / \mathrm{Au}$-NP sample is due to the ISHE induced by spin currents in the Pt layer. Significantly,
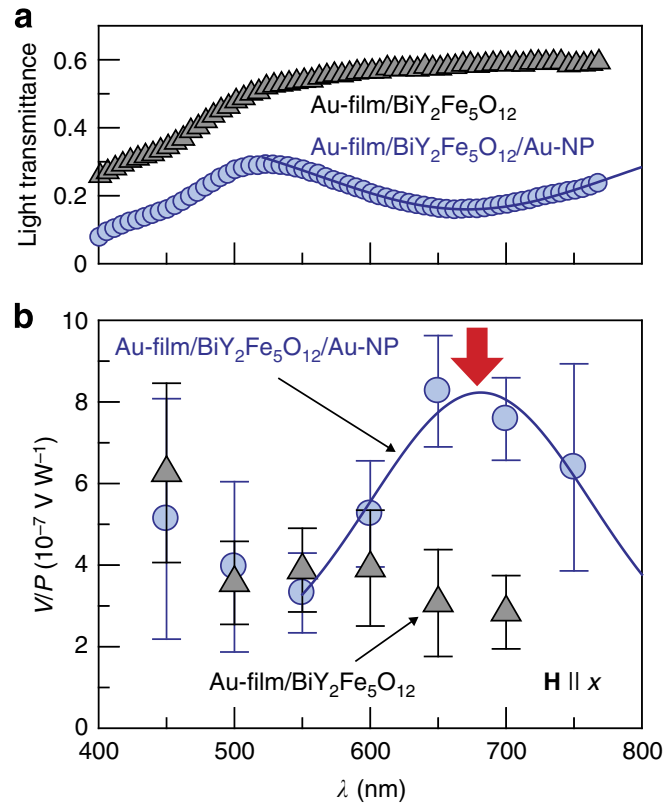

Figure 5 | Measurements using Au film. (a) $\lambda$ dependence of the light transmittance of the $\mathrm{Au}$-film/ $/ \mathrm{BiY}_{2} \mathrm{Fe}_{5} \mathrm{O}_{12} / \mathrm{Au}-\mathrm{NP}$ and $\mathrm{Au}$-film/BiY ${ }_{2} \mathrm{Fe}_{5} \mathrm{O}_{12}$ samples. (b) $\lambda$ dependence of $V / P$ in the $A u$-film/ $/ \mathrm{BiY}_{2} \mathrm{Fe}_{5} \mathrm{O}_{12} / \mathrm{Au}-\mathrm{NP}$ and Au-film/BiY ${ }_{2} \mathrm{Fe}_{5} \mathrm{O}_{12}$ samples, measured when $\mathbf{H}$ of $H=200$ Oe was applied along the $x$ direction. The $\mathrm{Au}$-film/ $/ \mathrm{BiY}_{2} \mathrm{Fe}_{5} \mathrm{O}_{12} / \mathrm{Au}-\mathrm{NP}$ sample was illuminated with monochromatic light with the wavelength $\lambda$, power $P$, bandwidth of $50 \mathrm{~nm}$ and spot diameter of $\sim 5 \mathrm{~mm}$ from the Au-film side at normal incidence.

Fig. $4 \mathrm{~b}$ shows that the $V / P$ signal in the $\mathrm{Pt} / \mathrm{BiY}_{2} \mathrm{Fe}_{5} \mathrm{O}_{12} / \mathrm{Au}-\mathrm{NP}$ sample exhibits peak structure and is markedly enhanced around $\lambda=690 \mathrm{~nm}$. This peak position in the $V / P$ spectrum coincides with the SPR wavelength of this $\mathrm{Pt} / \mathrm{BiY}_{2} \mathrm{Fe}_{5} \mathrm{O}_{12} / \mathrm{Au}-\mathrm{NP}$ sample (Fig. 4a,b). As both the $\mathrm{Pt} / \mathrm{BiY}_{2} \mathrm{Fe}_{5} \mathrm{O}_{12} / \mathrm{Au}-\mathrm{NP}$ and $\mathrm{Pt} / \mathrm{BiY}_{2} \mathrm{Fe}_{5} \mathrm{O}_{12}$ samples are illuminated from the Pt-film side, the temperature rise of the Pt layer is almost the same for both, confirming that the heating of the Pt layer is irrelevant to the ISHE enhancement under the SPR condition in the $\mathrm{Pt} / \mathrm{BiY}_{2} \mathrm{Fe}_{5} \mathrm{O}_{12} / \mathrm{Au}-\mathrm{NP}$ sample (see Supplementary Fig. 4 and Supplementary Note 1), where we note again that the background heating signal does not exhibit strong $\lambda$ dependence. This peak $V / P$ structure in the $\mathrm{Pt} / \mathrm{BiY}_{2} \mathrm{Fe}_{5} \mathrm{O}_{12} / \mathrm{Au}$-NP sample also cannot be explained by the heating of $\mathrm{Au}$ NPs or the $\mathrm{BiY}_{2} \mathrm{Fe}_{5} \mathrm{O}_{12}$ layer under the SPR condition because of the different sign; if the $\mathrm{BiY}_{2} \mathrm{Fe}_{5} \mathrm{O}_{12}$ layer was heated by electromagnetic loss in Au NPs, the ISHE voltage should decrease under the SPR condition as the temperature gradient generated by the Au-NP heating across the $\mathrm{Pt} / \mathrm{BiY}_{2} \mathrm{Fe}_{5} \mathrm{O}_{12}$ interface is of an opposite sign to the case when the $\mathrm{Pt}$ layer is heated (see Supplementary Fig. 4 and Supplementary Note 1). A possible slight heating of Au NPs in the off-resonance region might reduce the magnitude of the background signal slightly, but is also irrelevant to the $V / P$ signal with the positive peak structure. Our numerical calculations of electromagnetic field distributions based on the FDTD method show that the electromagnetic coupling between the Pt film and $\mathrm{Au}$ NPs under the SPR condition is too weak to explain the enhancement of the ISHE signal in the $\mathrm{Pt} / \mathrm{BiY}_{2} \mathrm{Fe}_{5} \mathrm{O}_{12} / \mathrm{Au}-\mathrm{NP}$ sample; as no SPR mode due to the coupling appears in the configuration used in this study, the temperature rise of the Pt layer is not changed by the SPR in Au NPs (Supplementary Figs 1 and 2).

We also performed control experiments by using different materials. We found that similar $V / P$ signals appear in a 

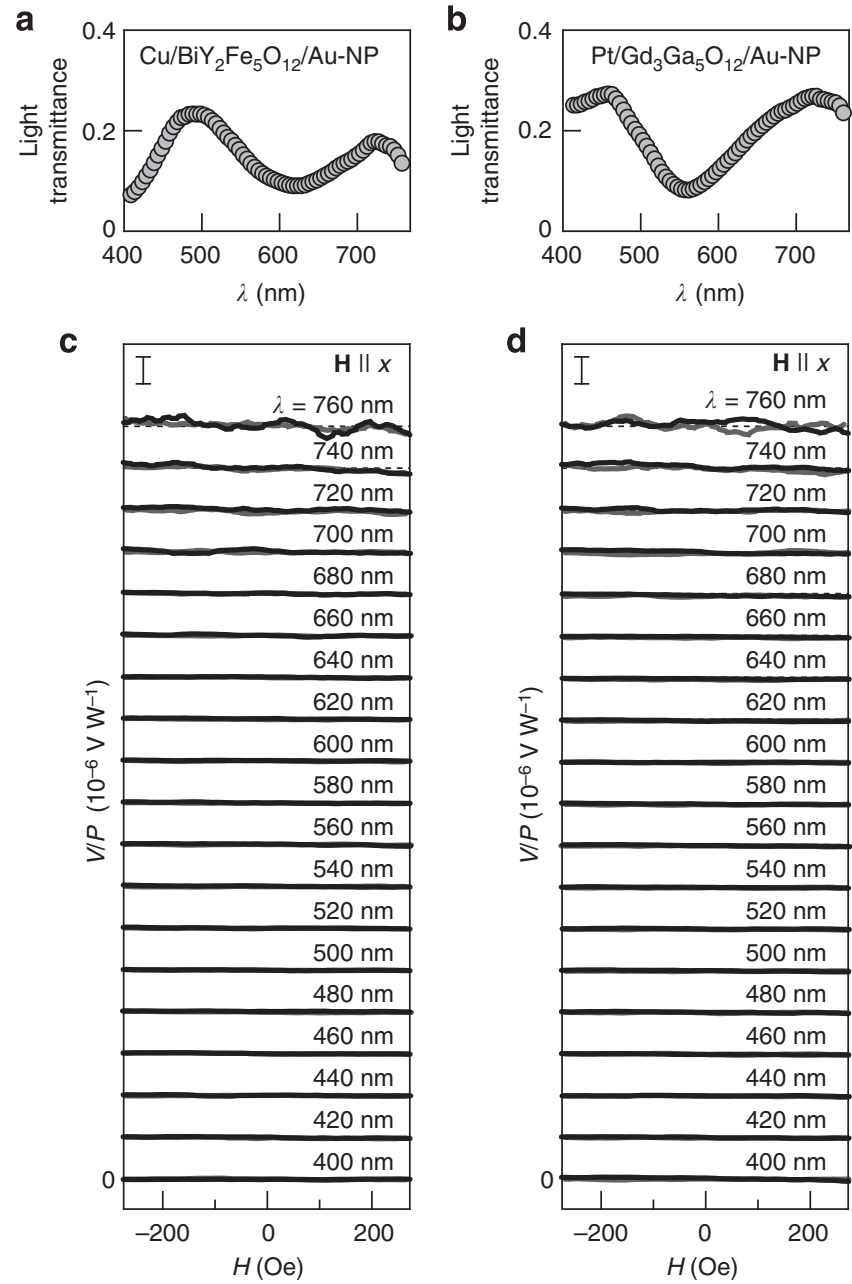

Figure 6 | Control experiments using different materials. (a,b) $\lambda$ dependence of the light transmittance of the $\mathrm{Cu} / \mathrm{BiY}_{2} \mathrm{Fe}_{5} \mathrm{O}_{12} / \mathrm{Au}-\mathrm{NP}$ (a) and Pt/ $\mathrm{Gd}_{3} \mathrm{Ga}_{5} \mathrm{O}_{12} / \mathrm{Au}-\mathrm{NP}$ (b) samples. (c,d) $\mathrm{H}$ dependence of $\mathrm{V} / \mathrm{P}$ in the $\mathrm{Cu} / \mathrm{BiY}_{2} \mathrm{Fe}_{5} \mathrm{O}_{12} / \mathrm{Au}-\mathrm{NP}$ (c) and $\mathrm{Pt} / \mathrm{Gd}_{3} \mathrm{Ga}_{5} \mathrm{O}_{12} / \mathrm{Au}-\mathrm{NP}$ (d) samples for various values of $\lambda(=760,740, \ldots, 400 \mathrm{~nm})$, measured when $\mathbf{H}$ was along the $x$ direction. The scale bars represent $V / P=20 \times 10^{-6} V_{W}^{-1}$. All the control experiments were performed by using the samples of a $10 \mathrm{~mm} \times 5 \mathrm{~mm}$ rectangular shape.

Au-film $/ \mathrm{BiY}_{2} \mathrm{Fe}_{5} \mathrm{O}_{12} / \mathrm{Au}-\mathrm{NP}$ sample, where the Pt film is replaced with a 5 -nm-thick Au film (Fig. 5a,b); as Au is a typical metal far from ferromagnetism ${ }^{29,30}$, proximity ferromagnetism in $\mathrm{Pt}$ cannot be the origin of the observed peak voltage structure. In contrast, this voltage signal was found to disappear in a $\mathrm{Cu} / \mathrm{BiY}_{2} \mathrm{Fe}_{5} \mathrm{O}_{12} / \mathrm{Au}-\mathrm{NP}$ sample, where the $\mathrm{Pt}$ layer is replaced with a 5 -nm-thick $\mathrm{Cu}$ film in which the spin-orbit interaction is very weak, indicating the important role of spin-orbit interaction, or the ISHE, in the voltage generation (Fig. $6 \mathrm{a}, \mathrm{c}$ ). The voltage signal also disappears in a $\mathrm{Pt} / \mathrm{Gd}_{3} \mathrm{Ga}_{5} \mathrm{O}_{12} / \mathrm{Au}$-NP sample, where $\mathrm{Au}$ NPs are embedded in a paramagnetic insulator $\mathrm{Gd}_{3} \mathrm{Ga}_{5} \mathrm{O}_{12}$ film instead of $\mathrm{BiY}_{2} \mathrm{Fe}_{5} \mathrm{O}_{12}$ (see Fig. 6b,d and Methods), indicating that direct contact between $\mathrm{BiY}_{2} \mathrm{Fe}_{5} \mathrm{O}_{12}$ and $\mathrm{Pt}$ is necessary for the observed voltage generation; electromagnetic artefacts are irrelevant. All the control experiments support our interpretation that the enhancement of the ISHE signal under the SPR condition in the $\mathrm{Pt} / \mathrm{BiY}_{2} \mathrm{Fe}_{5} \mathrm{O}_{12} / \mathrm{Au}$-NP sample results from the plasmonic spin pumping.

Separation of plasmonic spin pumping from heating effects. To further verify the effect of surface plasmons on the spin-current
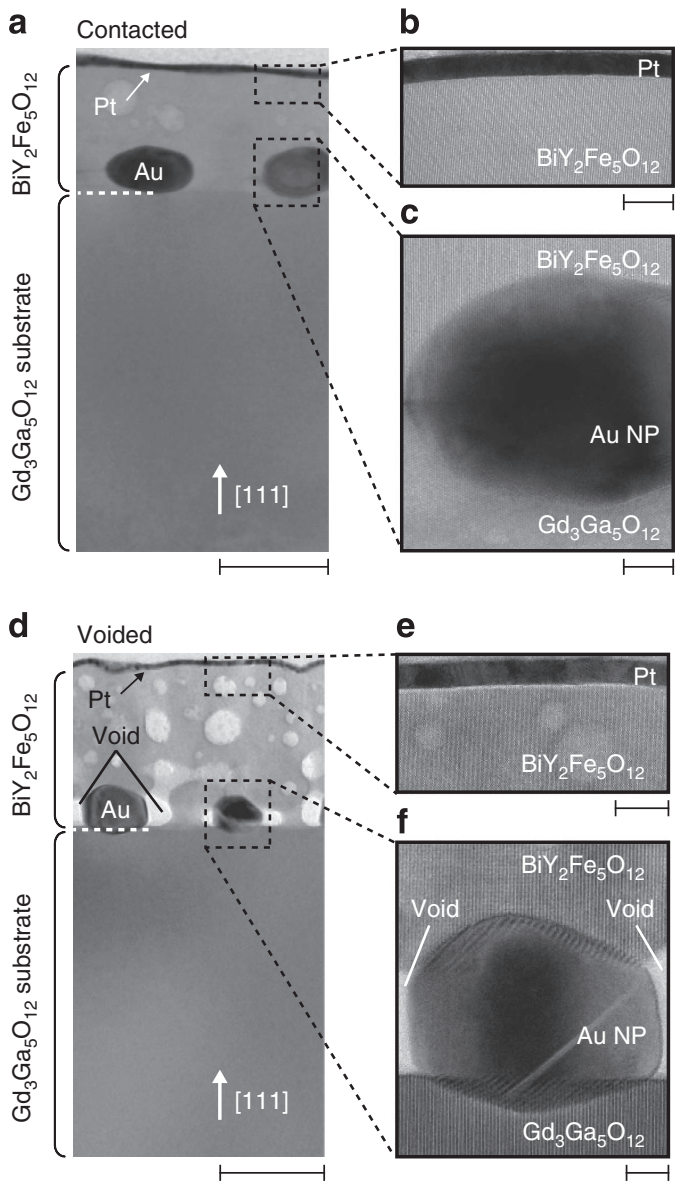

Figure 7 | Cross-sectional images. (a) Cross-sectional transmission electron microscope (TEM) images of the contacted $\mathrm{Pt} / \mathrm{BiY}_{2} \mathrm{Fe}_{5} \mathrm{O}_{12} / \mathrm{Au}-\mathrm{NP}$ sample. (b,c) Magnified TEM images of the contacted $\mathrm{Pt} / \mathrm{BiY}_{2} \mathrm{Fe}_{5} \mathrm{O}_{12} /$ Au-NP sample near the Pt film (b) and the Au NP (c). (d) Cross-sectional TEM images of the voided $\mathrm{Pt} / \mathrm{BiY}_{2} \mathrm{Fe}_{5} \mathrm{O}_{12} / \mathrm{Au}-\mathrm{NP}$ sample. (e,f) Magnified TEM images of the voided $\mathrm{Pt} / \mathrm{BiY}_{2} \mathrm{Fe}_{5} \mathrm{O}_{12} / \mathrm{Au}-\mathrm{NP}$ sample near the Pt film (e) and the Au NP (f). Scale bars in (a) and (d) (b,c,e and f) represent $100 \mathrm{~nm}(10 \mathrm{~nm})$. White arrows in (a) and (d) represent the crystal orientation of the $\mathrm{Gd}_{3} \mathrm{Ga}_{5} \mathrm{O}_{12}$ substrate. The voided $\mathrm{Pt} / \mathrm{BiY}_{2} \mathrm{Fe}_{5} \mathrm{O}_{12} / \mathrm{Au}-\mathrm{NP}$ sample has small voids with the size of $20-30 \mathrm{~nm}$ between the $\mathrm{BiY}_{2} \mathrm{Fe}_{5} \mathrm{O}_{12}$ film and $\mathrm{Au} N \mathrm{NP}_{\mathrm{s}}$, while Au NPs in the contacted sample are densely embedded in $\mathrm{BiY}_{2} \mathrm{Fe}_{5} \mathrm{O}_{12}$.

generation, we measured the $V / P$ spectra in the $\mathrm{Pt} / \mathrm{BiY}_{2} \mathrm{Fe}_{5} \mathrm{O}_{12} /$ Au-NP samples on changing the contact condition between $\mathrm{BiY}_{2} \mathrm{Fe}_{5} \mathrm{O}_{12}$ and $\mathrm{Au}$ NPs. Here, we prepared the $\mathrm{Pt} / \mathrm{BiY}_{2} \mathrm{Fe}_{5} \mathrm{O}_{12} /$ Au-NP samples by means of two different annealing conditions for the $\mathrm{BiY}_{2} \mathrm{Fe}_{5} \mathrm{O}_{12}$ layer (see Methods for details). In the $\mathrm{Pt} / \mathrm{BiY}_{2} \mathrm{Fe}_{5} \mathrm{O}_{12} / \mathrm{Au}-\mathrm{NP}$ sample used for the experiments in Fig. 4, $\mathrm{Au}$ NPs are densely embedded in the $\mathrm{BiY}_{2} \mathrm{Fe}_{5} \mathrm{O}_{12}$ film (Fig. $7 \mathrm{a}-\mathrm{c}$ ), where the peak V/P structure appears under the SPR condition (Fig. 8a-d). In contrast, we also fabricate the $\mathrm{Pt} / \mathrm{BiY}_{2} \mathrm{Fe}_{5} \mathrm{O}_{12} /$ Au-NP sample in which the Au NPs are separated from the $\mathrm{BiY}_{2} \mathrm{Fe}_{5} \mathrm{O}_{12}$ film by small voids (Fig. 7d-f), which interrupt the interaction between magnons in $\mathrm{BiY}_{2} \mathrm{Fe}_{5} \mathrm{O}_{12}$ and surface plasmons in Au NPs as the evanescent electromagnetic fields generated by the SPR are localized in the vicinity of Au NPs (Supplementary Fig. 5). The difference in the SPR wavelength between the 'contacted' and 'voided' $\mathrm{Pt} / \mathrm{BiY}_{2} \mathrm{Fe}_{5} \mathrm{O}_{12} / \mathrm{Au}-\mathrm{NP}$ samples is attributed to the difference in the dielectric constant of the medium around Au NPs; As Au NPs in the voided $\mathrm{Pt} / \mathrm{BiY}_{2} \mathrm{Fe}_{5} \mathrm{O}_{12} / \mathrm{Au}-\mathrm{NP}$ sample are surrounded by voids, its SPR 

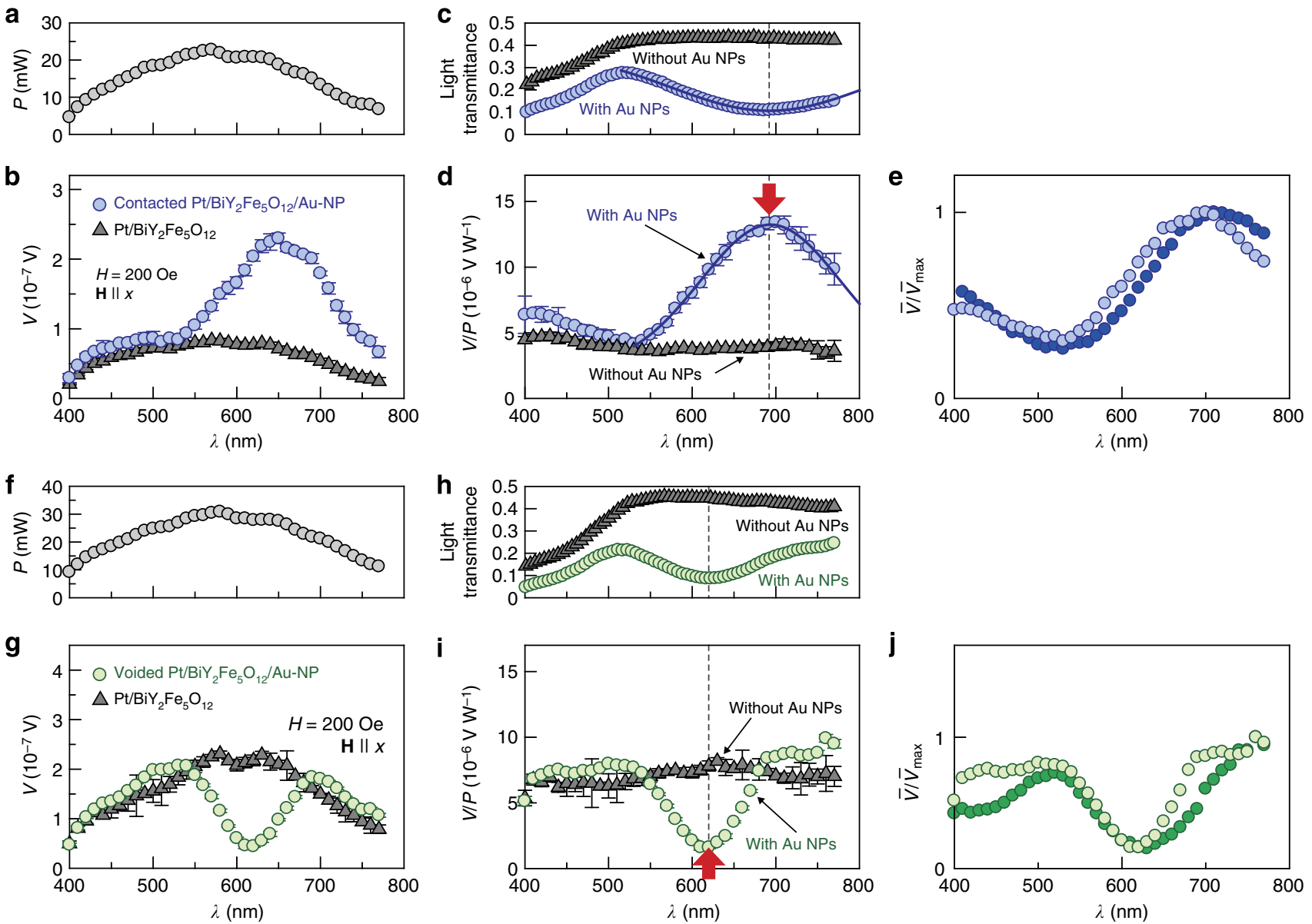

Figure 8 | Evidence for magnon excitation by surface plasmons. (a) $\lambda$ dependence of $P$, applied when the data in (b) were measured. (b) $\lambda$ dependence of $\mathrm{V}$ in the contacted $\mathrm{Pt} / \mathrm{BiY}_{2} \mathrm{Fe}_{5} \mathrm{O}_{12} / \mathrm{Au}-\mathrm{NP}$ and $\mathrm{Pt} / \mathrm{BiY}_{2} \mathrm{Fe}_{5} \mathrm{O}_{12}$ samples, measured when $\mathbf{H}$ of $H=200$ Oe was applied along the $x$ direction. The error bars represent the s.d. of the measurements. (c) $\lambda$ dependence of the light transmittance of the contacted Pt/BiY $\mathrm{Fe}_{5} \mathrm{O}_{12} / \mathrm{Au}^{\mathrm{N}} \mathrm{NP}$ and $\mathrm{Pt} / \mathrm{BiY}{ }_{2} \mathrm{Fe}_{5} \mathrm{O}_{12}$ samples. (d) $\lambda$ dependence of $V / P$ in the contacted Pt/BiY ${ }_{2} \mathrm{Fe}_{5} \mathrm{O}_{12} / \mathrm{Au}-\mathrm{NP}$ and $\mathrm{Pt} / \mathrm{BiY}_{2} \mathrm{Fe}_{5} \mathrm{O}_{12}$ samples. (e) $\lambda$ dependence of $\bar{V} / \bar{V}_{\text {max }}$ in two different contacted $\mathrm{Pt} / \mathrm{BiY}_{2} \mathrm{Fe}_{5} \mathrm{O}_{12} / \mathrm{Au}-\mathrm{NP}$ samples, where $\bar{V} \equiv V / P$ and $\bar{V}_{\max }$ is the maximum value of $\bar{V}$ in the $\lambda-\bar{V}$ spectrum. (f-j) Experimental results for the voided $\mathrm{Pt} / \mathrm{BiY}_{2} \mathrm{Fe}_{5} \mathrm{O}_{12} / \mathrm{Au}-\mathrm{NP}$ and $\mathrm{Pt} / \mathrm{BiY}_{2} \mathrm{Fe}_{5} \mathrm{O}_{12}$ samples. (j) shows the $\lambda$ dependence of $\bar{V} / \bar{V}_{\text {max }}$ in two different voided $\mathrm{Pt} / \mathrm{BiY}{ }_{2} \mathrm{Fe}_{5} \mathrm{O}_{12} / \mathrm{Au}-\mathrm{NP}$ samples.

wavelength is closer to that of plain $\mathrm{Au}$ NPs without $\mathrm{BiY}_{2} \mathrm{Fe}_{5} \mathrm{O}_{12}$ (compare Figs $2 \mathrm{a}$ and $8 \mathrm{c}, \mathrm{h}$ ). In the voided $\mathrm{Pt} / \mathrm{BiY}_{2} \mathrm{Fe}_{5} \mathrm{O}_{12} / \mathrm{Au}-\mathrm{NP}$ sample, dip structure was found to appear in the V/P spectrum under the SPR condition (Fig. 8f-i). This behaviour was observed not only in one sample but also in our different samples as exemplified in Fig. 8e,j. The dip V/P signal in the voided $\mathrm{Pt} / \mathrm{BiY}_{2} \mathrm{Fe}_{5} \mathrm{O}_{12} / \mathrm{Au}$-NP sample is attributed to the heating of $\mathrm{Au}$ NPs by the SPR, which generates the temperature gradient across the $\mathrm{Pt} / \mathrm{BiY}_{2} \mathrm{Fe}_{5} \mathrm{O}_{12}$ interface and the longitudinal spin Seebeck voltage along the direction opposite to the case when the Pt layer is heated (see Supplementary Figs 4,5 and Supplementary Note 1). These results indicate that the enhancement of the ISHE under the SPR condition, observed in the contacted $\mathrm{Pt} / \mathrm{BiY}_{2} \mathrm{Fe}_{5} \mathrm{O}_{12} / \mathrm{Au}-\mathrm{NP}$ sample, requires direct contact between the $\mathrm{BiY}_{2} \mathrm{Fe}_{5} \mathrm{O}_{12}$ and the Au NPs and cannot be explained by conventional heating effects, providing evidence for the operation of the plasmonic spin pumping due to nonequilibrium magnons excited by surface plasmons.

\section{Discussion}

The above experiments clearly show that the spin current generated by the light illumination in the contacted $\mathrm{Pt} / \mathrm{BiY}_{2} \mathrm{Fe}_{5} \mathrm{O}_{12} / \mathrm{Au}-\mathrm{NP}$ sample is strongly enhanced under the
SPR condition, and this enhancement is not connected to extrinsic heating effects. So then, what is the origin of the spin current under the SPR condition? Following previous studies on the incoherent spin pumping ${ }^{31,32}$, to generate the positive ISHE voltage in the present configuration, magnons in the $\mathrm{BiY}_{2} \mathrm{Fe}_{5} \mathrm{O}_{12}$ layer should be excited (see Supplementary Notes 1 and 2). A potential candidate for the magnon-excitation mechanism in the present sample structure is the strong evanescent electromagnetic fields (near-field photons) concomitant with surface plasmons. If the near-field photons excite magnons via the magnon-photon interaction ${ }^{33-36}$ near the $\mathrm{BiY}_{2} \mathrm{Fe}_{5} \mathrm{O}_{12} / \mathrm{Au}-\mathrm{NP}$ interface, the excited magnons in the $\mathrm{BiY}_{2} \mathrm{Fe}_{5} \mathrm{O}_{12}$ layer produce a spin current owing to the incoherent spin-pumping mechanism and the positive ISHE voltage in the Pt layer: this is the plasmonic spin pumping. Using a standard many-body technique, we formulate theoretically the plasmonic spin pumping based on magnon-photon Raman scattering process (Supplementary Fig. 6). The spin current pumped by light illumination is described as

$$
J_{\mathrm{S}}=\Gamma^{+} \Gamma^{-} G_{\mathrm{S}} \frac{\hbar v a_{\mathrm{S}}^{4}}{c \alpha}|E|^{2}
$$

within the linear response region (see Supplementary Note 2 for details). Here, $\Gamma^{+(-)}$is the dimensionless magnon-photon coupling constant, $G_{\mathrm{S}}$ the strength of the magnetic coupling at the 
$\mathrm{Pt} / \mathrm{BiY}_{2} \mathrm{Fe}_{5} \mathrm{O}_{12}$ interface, $\hbar$ the Planck constant divided by $2 \pi, v$ the photon frequency, $c$ the velocity of light, $a_{\mathrm{S}}^{3}$ the effective block spin volume, $\alpha$ the Gilbert damping constant and $E$ the electric field amplitude induced by surface plasmons. Equation (2) indicates that the plasmon-induced spin current in the $\mathrm{Pt} / \mathrm{BiY}_{2} \mathrm{Fe}_{5} \mathrm{O}_{12} / \mathrm{Au}-\mathrm{NP}$ sample is proportional to the electromagnetic energy in the $\mathrm{BiY}_{2} \mathrm{Fe}_{5} \mathrm{O}_{12}$ layer $\left(\propto|E|^{2}\right)$, a situation consistent with the experimental results in Fig. $4 \mathrm{c}$ as $|E|^{2}$ generated by surface plasmons is proportional to the incident light power $P$. The observed peak ISHE voltage in the contacted $\mathrm{Pt} / \mathrm{BiY}_{2} \mathrm{Fe}_{5} \mathrm{O}_{12} / \mathrm{Au}-\mathrm{NP}$ sample is attributed to the strong evanescent electromagnetic fields enhanced by surface plasmons, while the spin current described by Equation (2) is undetectably small in the plain $\mathrm{Pt} / \mathrm{BiY}_{2} \mathrm{Fe}_{5} \mathrm{O}_{12}$ film due to the small energy transfer from external photons to magnons (see Supplementary Note 2). Note that the ratio of the voltage enhancement in Fig. $4 \mathrm{~b}$ does not correspond to that of the $|E|^{2}$ enhancement due to the presence of the background heating signal.

The plasmonic spin pumping observed here can be applied to the construction of light/spin-current convertors for driving spintronic devices. The plasmonic spin pumping also adds a light/ voltage conversion function to spin Seebeck thermoelectric devices $^{22}$, enabling hybrid voltage generation from both light and heat in a single device. The plasmonic spin pumping follows the same scaling law as the spin Seebeck effect: the output power is increased simply by extending the device area. This light/ voltage conversion is conceptually different from that based on a PN junction, and is free from the output-voltage limitation caused by built-in potential. Although the spin and electric voltages generated by the plasmonic spin pumping are still small, there is plenty of scope for performance improvement; they can be enhanced by using magnetic insulators with large magnonphoton coupling, improving magnetic-insulator/NP interfaces for efficient magnon-plasmon energy transfer, and introducing plasmonic crystals that exhibit sharp and strong SPR. Plasmonic spintronics based on the interaction between surface plasmons and spin currents is still in its infancy; more detailed experimental and theoretical investigations are necessary to obtain full understanding of the mechanism of the plasmonic spin pumping and to quantitatively evaluate plasmon-magnonelectron conversion efficiency, which might be realized by removing the size, position and shape variations of Au NPs.

\section{Methods}

Preparation process of $\mathbf{P t} / \mathbf{B i Y}_{2} \mathrm{Fe}_{5} \mathbf{O}_{12} / \mathbf{A u}-\mathrm{NP}$ samples. The Au NPs were formed by the following two-step procedures: fabrication of a 5-nm-thick Au thin film on a $\mathrm{Gd}_{3} \mathrm{Ga}_{5} \mathrm{O}_{12}$ (111) substrate by using a d.c. sputtering system and heating of the Au film at $1,000{ }^{\circ} \mathrm{C}$ for 30 min (ref. 6). To increase the density of Au NPs, these procedures were repeated three times. The $\mathrm{BiY}_{2} \mathrm{Fe}_{5} \mathrm{O}_{12}$ thin film was then formed by the MOD method ${ }^{22}$. The MOD solution for the contacted (voided) $\mathrm{Pt} / \mathrm{BiY}_{2} \mathrm{Fe}_{5} \mathrm{O}_{12} / \mathrm{Au}-\mathrm{NP}$ sample includes $\mathrm{Bi}$, $\mathrm{Y}$ and $\mathrm{Fe}$ carboxylates, dissolved in organic solvents with the concentration of $3 \%(5 \%)$. Its chemical composition is $\mathrm{Bi}: \mathrm{Y}: \mathrm{Fe}=1: 2: 5$. The solution for the contacted (voided) sample was spin-coated on the $\mathrm{Gd}_{3} \mathrm{Ga}_{5} \mathrm{O}_{12}$ substrate with Au NPs at 5,000 r.p.m. for 60 s, followed by a drying step at $50^{\circ} \mathrm{C}\left(170^{\circ} \mathrm{C}\right)$ for $3 \mathrm{~min}$ and pre-annealing at $480^{\circ} \mathrm{C}\left(550^{\circ} \mathrm{C}\right)$ for $1 \mathrm{~h}$ ( $5 \mathrm{~min}$ ). To increase the thickness of the $\mathrm{BiY}_{2} \mathrm{Fe}_{5} \mathrm{O}_{12}$ film, the processes from spincoating to pre-annealing were repeated three times. Then, the contacted (voided) sample was annealed at $725^{\circ} \mathrm{C}\left(680^{\circ} \mathrm{C}\right)$ for $15 \mathrm{~h}$ in air to form a crystallized $\mathrm{BiY}_{2} \mathrm{Fe}_{5} \mathrm{O}_{12}$ film. The cross-sectional transmission electron microscope images in Fig. 7 indicate that a crystalline $\mathrm{BiY}_{2} \mathrm{Fe}_{5} \mathrm{O}_{12}$ film was formed on the $\mathrm{Gd}_{3} \mathrm{Ga}_{5} \mathrm{O}_{12}$ substrate. Finally, a 5-nm-thick Pt film was deposited over the whole surface of the $\mathrm{BiY}_{2} \mathrm{Fe}_{5} \mathrm{O}_{12}$ film by using an rf magnetron sputtering.

Preparation process of $\mathbf{P t} / \mathbf{G d}_{\mathbf{3}} \mathbf{G a}_{\mathbf{5}} \mathbf{O}_{\mathbf{1 2}} / \mathbf{A u}-\mathbf{N P}$ sample. The $\mathrm{Pt} / \mathrm{Gd}_{3} \mathrm{Ga}_{5} \mathrm{O}_{12} /$ Au-NP sample used in Fig. $6 \mathrm{~b}, \mathrm{~d}$ consists of a $\mathrm{Pt} / \mathrm{Gd}_{3} \mathrm{Ga}_{5} \mathrm{O}_{12}$ bilayer film with $\mathrm{Au}$ NPs embedded in the $\mathrm{Gd}_{3} \mathrm{Ga}_{5} \mathrm{O}_{12}$ layer. After forming Au NPs on a $\mathrm{Gd}_{3} \mathrm{Ga}_{5} \mathrm{O}_{12}$ (111) substrate with the procedures described above, an additional $\mathrm{Gd}_{3} \mathrm{Ga}_{5} \mathrm{O}_{12}$ thin film was coated on them by means of the MOD method. The MOD solution for the $\mathrm{Gd}_{3} \mathrm{Ga}_{5} \mathrm{O}_{12}$ film includes $\mathrm{Gd}$ and $\mathrm{Ga}$ carboxylates, dissolved in organic solvents with the concentration of $3 \%$. Its chemical composition is $\mathrm{Gd}: \mathrm{Ga}=3: 5$. The spin-coating and annealing processes for the $\mathrm{Gd}_{3} \mathrm{Ga}_{5} \mathrm{O}_{12}$ film are the same as those for the $\mathrm{BiY}_{2} \mathrm{Fe}_{5} \mathrm{O}_{12}$ film in the contacted $\mathrm{Pt} / \mathrm{BiY}_{2} \mathrm{Fe}_{5} \mathrm{O}_{12} / \mathrm{Au}-\mathrm{NP}$ sample. Finally, a 5-nm-thick Pt film was deposited over the whole surface of the $\mathrm{Gd}_{3} \mathrm{Ga}_{5} \mathrm{O}_{12}$ film. The mean distance between the Pt film and Au NPs in the $\mathrm{Pt} / \mathrm{Gd}_{3} \mathrm{Ga}_{5} \mathrm{O}_{12} / \mathrm{Au}-\mathrm{NP}$ sample is $\sim 100 \mathrm{~nm}$, which is comparable to that in the $\mathrm{Pt} / \mathrm{BiY}_{2} \mathrm{Fe}_{5} \mathrm{O}_{12} / \mathrm{Au}-\mathrm{NP}$ sample.

Numerical calculation. To investigate the electromagnetic field distributions induced by surface plasmons, we performed the numerical calculation based on the FDTD method ${ }^{25}$ using KeyFDTD (Science Technology Research Institute, Japan). The simulation results shown in Fig. 3 were obtained from a model comprising a $\mathrm{BiY}_{2} \mathrm{Fe}_{5} \mathrm{O}_{12}$ rectangular parallelepiped with the size of $150 \mathrm{~nm} \times 150 \mathrm{~nm} \times 140 \mathrm{~nm}$ and a Au spheroid with the in-plane diameter $d_{\mathrm{Au}}$ of $70 \mathrm{~nm}$ and the height $h_{\mathrm{Au}}$ of $40 \mathrm{~nm}$ embedded at the centre of the $\mathrm{BiY}_{2} \mathrm{Fe}_{5} \mathrm{O}_{12}$, where the distance $L$ between the tops of the $\mathrm{BiY}_{2} \mathrm{Fe}_{5} \mathrm{O}_{12}$ and the $\mathrm{Au}$ is $50 \mathrm{~nm}$. The unit cell of the model is $2 \mathrm{~nm} \times 2 \mathrm{~nm} \times 1 \mathrm{~nm}$. A flat light source is placed on the top of the $\mathrm{BiY}_{2} \mathrm{Fe}_{5} \mathrm{O}_{12}$ rectangular parallelepiped in the $x-y$ plane, which generates plane electromagnetic waves with the polarization along the $x$ direction and the wave vector $\mathbf{k}$ along the $z$ direction (note that the incident light used in the experiments is unpolarized). Here, the $x, y$ and $z$ directions are defined in Fig. 3a. At the outer boundaries of the $\mathrm{BiY}_{2} \mathrm{Fe}_{5} \mathrm{O}_{12}$, we set a periodic boundary condition. Under this condition, we calculated the distribution of the electric field intensity $|E|$ while fixing the wavelength of the incident electromagnetic waves. In Fig. 3b,c, we plot the $|E|$ distribution in the $\mathrm{BiY}_{2} \mathrm{Fe}_{5} \mathrm{O}_{12} / \mathrm{Au}-\mathrm{NP}$ model in the $x-y$ plane across the centre of the Au spheroid. By using the FDTD method and similar models, we have also investigated the electromagnetic coupling between the Pt film and Au NPs in the $\mathrm{Pt} / \mathrm{BiY}_{2} \mathrm{Fe}_{5} \mathrm{O}_{12} / \mathrm{Au}-\mathrm{NP}$ sample, which might affect the voltage signal under the SPR condition, by comparing the simulated distributions of $|E|$ induced by the SPR between the $\mathrm{BiY}_{2} \mathrm{Fe}_{5} \mathrm{O}_{12} / \mathrm{Au}-\mathrm{NP}$ models with and without the Pt layer for various values of $L, d_{\mathrm{Au}}$ and $h_{\mathrm{Au}}$ (Supplementary Figs 1 and 2). In Supplementary Fig. 5, we compare the simulated $|E|$ distributions between the $\mathrm{Pt} / \mathrm{BiY}_{2} \mathrm{Fe}_{5} \mathrm{O}_{12} / \mathrm{Au}-\mathrm{NP}$ models with and without a void. The refraction index and absorption-constant spectra of $\mathrm{BiY}_{2} \mathrm{Fe}_{5} \mathrm{O}_{12}, \mathrm{Au}$ and $\mathrm{Pt}$ in the calculations were obtained from refs 37-39, respectively.

\section{References}

1. Barnes, W. L., Dereux, A. \& Ebbesen, T. W. Surface plasmon subwavelength optics. Nature 424, 824-830 (2003).

2. Hutter, E. \& Fendler, J. H. Exploitation of localized surface plasmon resonance Adv. Mater. 16, 1685-1706 (2004).

3. Raghu, S., Chung, S. B., Qi, X.-L. \& Zhang, S.-C. Collective modes of a helical liquid. Phys. Rev. Lett. 104, 116401 (2010).

4. Appelbaum, I., Drew, H. D. \& Fuhrer, M. S. Proposal for a topological plasmon spin rectifier. Appl. Phys. Lett. 98, 023103 (2011).

5. Di Pietro, P. et al. Observation of Dirac plasmons in a topological insulator. Nat. Nanotechnol. 8, 556-560 (2013).

6. Uchida, H., Masuda, Y., Fujikawa, R., Baryshev, A. V. \& Inoue, M. Large enhancement of Faraday rotation by localized surface plasmon resonance in $\mathrm{Au}$ nanoparticles embedded in Bi:YIG film. J. Magn. Magn. Mat. 321, 843-845 (2009).

7. Melander, E. et al. Influence of the magnetic field on the plasmonic properties of transparent Ni anti-dot arrays. Appl. Phys. Lett. 101, 063107 (2012).

8. Wolf, S. A. et al. Spintronics: a spin-based electronics vision for the future. Science 294, 1488-1495 (2001).

9. Žutić, I., Fabian, J. \& Das Sarma, S. Spintronics: fundamentals and applications Rev. Mod. Phys. 76, 323-410 (2004).

10. Slonczewski, J. C. Current-driven excitation of magnetic multilayers. J. Magn. Magn. Mat. 159, L1-L7 (1996).

11. Maekawa, S., Saitoh, E., Valenzuela, S. O. \& Kimura, T. (Eds). Spin Current (Oxford University Press, 2012).

12. Tserkovnyak, Y., Brataas, A. \& Bauer, G. E. W. Enhanced Gilbert damping in thin ferromagnetic films. Phys. Rev. Lett. 88, 117601 (2002).

13. Mizukami, S., Ando, Y. \& Miyazaki, T. Effect of spin diffusion on Gilbert damping for a very thin permalloy layer in $\mathrm{Cu} /$ permalloy/Cu/Pt films. Phys Rev. B 66, 104413 (2002).

14. Saitoh, E., Ueda, M., Miyajima, H. \& Tatara, G. Conversion of spin current into charge current at room temperature: inverse spin-Hall effect. Appl. Phys. Lett. 88, 182509 (2006).

15. Kajiwara, Y. et al. Transmission of electrical signals by spin-wave interconversion in a magnetic insulator. Nature 464, 262-266 (2010).

16. Uchida, K. et al. Observation of the spin Seebeck effect. Nature 455, 778-781 (2008).

17. Xiao, J., Bauer, G. E. W., Uchida, K., Saitoh, E. \& Maekawa, S. Theory of magnon-driven spin Seebeck effect. Phys. Rev. B 81, 214418 (2010).

18. Uchida, K. et al. Spin Seebeck insulator. Nat. Mater. 9, 894-897 (2010).

19. Jaworski, C. M. et al. Observation of the spin-Seebeck effect in a ferromagnetic semiconductor. Nat. Mater. 9, 898-903 (2010). 
20. Uchida, K. et al. Observation of longitudinal spin-Seebeck effect in magnetic insulators. Appl. Phys. Lett. 97, 172505 (2010).

21. Adachi, H., Ohe, J., Takahashi, S. \& Maekawa, S. Linear-response theory of spin Seebeck effect in ferromagnetic insulators. Phys. Rev. B 83, 094410 (2011).

22. Kirihara, A. et al. Spin-current-driven thermoelectric coating. Nat. Mater. 11, 686-689 (2012)

23. Kikkawa, T. et al. Longitudinal spin Seebeck effect free from the proximity Nernst effect. Phys. Rev. Lett. 110, 067207 (2013).

24. Kikkawa, T. et al. Separation of longitudinal spin Seebeck effect from anomalous Nernst effect: determination of the origin of transverse thermoelectric voltage in metal/insulator junctions. Phys. Rev. B 88, 214403 (2013).

25. Mur, G. Absorbing boundary conditions for the finite-difference approximation of the time-domain electromagnetic-field equations. IEEE Trans. Electromagn. Compat. EMC-23, 377-382 (1981)

26. Valenzuela, S. O. \& Tinkham, M. Direct electronic measurement of the spin Hall effect. Nature 442, 176-179 (2006).

27. Kimura, T., Otani, Y., Sato, T., Takahashi, S. \& Maekawa, S. Room-temperature reversible spin Hall effect. Phys. Rev. Lett. 98, 156601 (2007).

28. Huang, S. Y. et al. Transport magnetic proximity effects in platinum. Phys. Rev. Lett. 109, 107204 (2012).

29. Ibach, H. \& Luth, H. Solid-State Physics: an Introduction to Principles of Materials Science (Springer, 2009).

30. Papaconstantopoulos, D. A. Handbook of the Band Structure of Elemental Solids (Plenum Press, 1986).

31. Uchida, K. et al. Long-range spin Seebeck effect and acoustic spin pumping. Nat. Mater. 10, 737-741 (2011).

32. Uchida, K. et al. Acoustic spin pumping: direct generation of spin currents from sound waves in $\mathrm{Pt} / \mathrm{Y}_{3} \mathrm{Fe}_{5} \mathrm{O}_{12}$ hybrid structures. J. Appl. Phys. 111, 053903 (2012).

33. Elliott, R. J. \& Loudon, R. The possible observation of electronic Raman transitions in crystals. Phys. Lett. 3, 189-191 (1963).

34. Shen, Y. R. \& Bloembergen, N. Interaction between light waves and spin waves. Phys. Rev. 143, 372-384 (1966).

35. Moriya, T. Theory of light scattering by magnetic crystals. J. Phys. Soc. Jpn 23, 490-500 (1967)

36. Fleury, P. A. \& Loudon, R. Scattering of light by one- and two-magnon excitations. Phys. Rev. 166, 514-530 (1968).

37. Doormann, V., Krumme, J.-P., Klages, C.-P. \& Erman, M. Measurement of the refractive index and optical absorption spectra of epitaxial bismuth substituted yttrium iron garnet films at uv to near-ir wavelengths. Appl. Phys. A 34, 223-230 (1984)
38. Johnson, P. B. \& Christy, R. W. Optical constants of the noble metals. Phys. Rev. B 6, 4370-4379 (1972).

39. Palik, E. D. Handbook of Optical Constants of Solids (Academic Press, 1985).

\section{Acknowledgements}

We thank Y. Ohnuma, T. Kikkawa, S. Daimon, A. Kirihara, M. Ishida, T. Meyer, M. Agrawal, E. Papaioannou and B. Hillebrands for valuable discussions. This work was supported by PRESTO-JST 'Phase Interfaces for Highly Efficient Energy Utilization', CREST-JST 'Creation of Nanosystems with Novel Functions through Process Integration', Grant-in-Aid for Young Scientists (A) (25707029), Grant-in-Aid for Scientific Research (A) (24244051), Grant-in-Aid for Scientific Research on Innovative Areas 'Nano Spin Conversion Science' (26103005) from MEXT, Japan, LC-IMR of Tohoku University, NEC Corporation, the Sumitomo Foundation, the Tanikawa Fund Promotion of Thermal Technology, the Casio Science Promotion Foundation and the Iwatani Naoji Foundation.

\section{Author contributions}

K.U. and E.S. planned and supervised the study. K.U. designed the experiments, prepared the samples, collected and analysed all of the data and performed the numerical calculation. H.A. and S.M. developed the explanation of the experiments. D.K. performed the scanning electron microscopy. S.I. performed the transmission electron microscopy. Z.Q. supported the sample preparation. K.U. and H.A. wrote the manuscript with input from E.S. and S.M. All authors discussed the results.

\section{Additional information}

Supplementary Information accompanies this paper at http://www.nature.com/ naturecommunications

Competing financial interests: The authors declare no competing financial interests.

Reprints and permission information is available online at http://npg.nature.com/ reprintsandpermissions/

How to cite this article: Uchida, K. et al. Generation of spin currents by surface plasmon resonance. Nat. Commun. 6:5910 doi: 10.1038/ncomms6910 (2015).

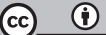

This work is licensed under a Creative Commons Attribution 4.0 International License. The images or other third party material in this article are included in the article's Creative Commons license, unless indicated otherwise in the credit line; if the material is not included under the Creative Commons license users will need to obtain permission from the license holder to reproduce the material To view a copy of this license, visit http://creativecommons.org/licenses/by/4.0/ 